\title{
PREEMPTIVE AND REACTIVE SPENDING IN U.S. HOUSE RACES
}

\author{
Edie N. Goldenberg, Michael W. Traugott, \\ and Frank R. Baumgartner
}

\begin{abstract}
This paper examines the spending behavior of candidates for the U.S. House of Representatives. Particular attention is paid to the timing of receipts and expenditures over the complete 2-year election cycle. Incumbents raise and spend large amounts of money very early in the race, and this preemptive spending may have a great impact on the selection of challengers and therefore on electoral outcomes. In addition, a model of reactive spending is tested for the general election period. Incumbents' expenditures are a function of the underlying partisan division in the district, the strength of the challenge, and candidates' feelings of vulnerability. Incumbents are strategic actors who attempt to maximize their chances of reelection. Early in the term, they spend preemptively in an effort to influence the selection of their challengers. Later in the term, they spend in reaction to the strength of their challengers' campaign. The role of money in congressional campaigns is neither simple nor direct. More attention needs to be given to the strategic uses of money in the period leading up to the general election campaign as well as to the dynamics of receipts and expenditures over an entire election cycle.
\end{abstract}

Past scholarly work on the uses and consequences of money in campaigns has emphasized the direct effects of money spent on winning general elections. But incumbents spend for many different reasons, only one of which is to guarantee victory in a general election race with a particular challenger. Candidates for the U.S. House of Representatives are assembling war chests of campaign funds earlier in the 2-year cycle and in greater quantity than ever before; and most incumbents are finishing their campaigns with substantial cash balances, which they carry over to the next electoral cycle. These actions raise new questions about the strategic uses of money in campaigns as it becomes clear that not all of the incumbents'

Edie N. Coldenberg, Michael W. Traugott, and Frank R. Baumgartner, Center for Political Studies, The University of Michigan.

Political Behavior

(C) 1986 Agathon Press, Inc.

Vol. 8, No. 1 
funds are being raised or spent in the traditional general election period to defeat a known challenger.

The timing of fund-raising across the biennial electoral cycle, the symbolic importance of large cash balances, and the use of surpluses from previous campaigns are new weapons for incumbents in their pursuit of increased seniority. Interested in securing reelection, they have the potential to use money to affect decisions about who their challengers might be-in the context of the current race as well as in the future. In this sense, incumbents clearly have the ability to spend "preemptively" in order to structure the nature of the contest which they will face.

The research reported here takes a broader perspective on the uses and consequences of money in campaigns by examining patterns of spending across the entire interelection period. The first section presents a review of recent research findings on campaign spending. Next, patterns of early spending by incumbents before their challengers are known are identified. Then a revised model of reactive spending is proposed and tested, and finally, by examining deviant cases, additional factors are identified that are likely to affect incumbents' spending behavior during the general election period.

\section{RESEARCH ON CAMPAIGN SPENDING}

Most research on the consequences of money in congressional elections pays little attention to the dynamic elements of continuous campaigning. To date this research has followed two separate but related paths. One has emphasized the process of financing campaigns, focusing upon contributors. The findings indicate that incumbents are clearly advantaged over their challengers in raising funds. Political Action Committees (PACs) with economic interests tend to support incumbents over challengers (Welch, 1980), and there is widespread concern about the implications of the increasing reliance of incumbents on the funds provided by special interest groups.

The other major path is concerned with the uses of a variety of resources in campaigns as they relate to electoral success. Previous work shows that incumbents approach the general election campaign period with substantial advantages. Cover (1977) and Cover and Brumberg (1982) emphasized the significance of perquisites of office; Fiorina (1977), their ombudsman's role; Mayhew (1974a and 1974b) and Fiorina (1974), their issue positions; Fenno (1978), their contact with constituents and trips back home to the district; Hinckley (1980) and Ragsdale (1981), their visibility advantage; and Jacobson (1978), the role of money.

As Jacobson (1978) demonstrated, high expenditures are not necessarily 
associated with large electoral margins. The more challengers spend, the better they do; but the more incumbents spend, the worse they do. Incumbents who spend a lot do so in response to serious opposition, leading to the seemingly counterintuitive relationship between their own effort and success. Thus the concept of "reactive spending" was born as a reflection of a candidate's investment in fund-raising and resulting levels of expenditure in response to the seriousness of the challenge.

Goldenberg and Traugott (1984) extended the concept of vulnerability through the use of survey-based measures of the candidates' chances of beating the opponent. Using a measure of uncertainty of the outcome, they show that even a distinction between incumbents and challengers is inadequate to explain levels of spending unless it also incorporates a measure of whether candidates think they can win or not. By distinguishing between an incumbent who is a "sure winner" as opposed to a "vulnerable" and between a challenger who is a "hopeful" as opposed to a "sure loser," an even greater explanation of levels of campaign spending is possible. In fact, there are classes of challengers (Hopefuls) who spend more on average than classes of incumbents (Sure Winners).

This concept of an incumbent's vulnerability is composed of two distinct factors. One is a short-term concern with the contest at hand and getting reelected. This is largely a function of the strength and resources of the challenger, but it might also result from a problem brought on by the incumbent since the last election such as a personal scandal. Some incumbents will have been targeted for attention by special interest groups which disagree with their voting records. Attacks by these groups provide ammunition for the opposition. In addition, they solicit their members for contributions to be used as independent expenditures in negative campaigns against the incumbent.

A second aspect of vulnerability derives from a concern with election realities that are present every 2 years regardless of the specific challenger. This form of vulnerability is largely a function of the distribution of partisanship in the district. The safety of the district can affect both the incumbent's perspective on career planning as well as the quality of the opposition that will emerge from the other party at some time in the future.

While either kind of vulnerability should lead to heavy spending in the general election period, there is a much more limited set of circumstances under which early or "preemptive" spending should appear even before an opponent is known. One is when a scandal has occurred during the current term; although such incidents are uncommon, they do affect some members in each term. A second is when the district has been historically competitive and strong challenges are quite common. And a third is when an incumbent has aspirations for higher office or for greater political clout 
in Congress in the form of a better committee assignment, a chairmanship, or some other leadership position.

Preemptive fund-raising and spending involve assembling cash in anticipation of a serious challenge, often when the specific challenger is unknown, as well as spending money in advance of the general election campaign in order to maintain contact with constituents and to dissuade serious challenges. In this formulation, time (or timing) assumes added importance because the model implies anticipatory spending behavior on the part of incumbents rather than just reactive spending. In the general election campaign, reactive spending may become unnecessary because potentially strong opponents have already dropped out of the pool of possible challengers in the face of large sums of money stockpiled by an apparently invincible incumbent. There is no reason to assume that incumbents are disinterested in who their challengers will be nor that they will sit back to find out who the other party will select as the most worthy opponent. Moreover, fully appreciating the dynamics of the process over successive elections, incumbents may work hard in the earlier stages of their career to insure that successive reelection efforts are easier.

For another class of candidates, large electoral margins may be the key to advancing their political careers. Some want to pursue positions of leadership and greater responsibility in the U.S. House of Representatives. Others seek elective office which involves a larger constituency - running for governor or for the U.S. Senate. In either case, demonstrating an ability to raise large sums of money and to win with large margins can increase their visibility and attractiveness as candidates for higher office. Making contributions to the campaigns of colleagues from the same state delegation or committee who have been less active or successful at raising money can cement alliances which will be useful later when party assignments are being handed out or when seeking higher office. And, of course, campaign surpluses provide a head start on fund raising for subsequent campaigns for statewide office that will inevitably be more expensive.

Until recently, scholars concentrated on general election spending behavior, although they were forced to rely upon 2-year expenditure totals provided by the Federal Election Commission (FEC) for their analyses. This reflected too narrow a definition of the campaign period and used an available but inadequate measure of spending behavior. Now, the process of continuous campaigning by incumbents is more clearly understood (Fenno, 1978), and researchers should broaden their view of spending behavior to take in the entire interelection period. Of equal significance, researchers can now examine spending over time, thereby overcoming a measurement problem which has delayed theoretical development. The current availability of more detailed receipt and expenditure data over 
time from the FEC makes the preliminary analysis of preemptive behavior possible.

Taking advantage of this opportunity, the research reported here rests upon two sets of analyses. The first, which must remain essentially descriptive, investigates the patterns of fund-raising and expenditures across the period from January 1, 1977, to December 31,1978 , for candidates in a representative national sample of contested congressional races. ${ }^{1}$ To pursue more detailed analyses of the effects of such behavior, particularly on the emergence of challengers, a novel and much more extensive data collection effort would have to be undertaken. This would involve identifying the pool of potential challengers in congressional races, including information on when they first thought about entering the race and what affected their decision to get out or stay in through the primary. Such information is not at present available, but it will be needed eventually in order to understand fully the consequences of the spending behavior of incumbents.

The second part of the analysis concentrates on reactive spending, testing a revised and simplified model with improved measures of central concepts. The results enhance the predictive capacity of the Jacobson model rather than challenge it, and suggest fruitful avenues for future research on the effects of money in congressional elections.

\section{PATTERNS OF CANDIDATE SPENDING OVER TIME}

The importance of the strategic uses of campaign funds is highlighted when patterns of campaign spending are viewed over time. As the costs of campaigning have increased, so have the candidates' capacities to raise funds, particularly incumbents. While some may complain about the effort involved in soliciting contributions, they nevertheless demonstrate increasing success, as measured by receipts. In fact, very few incumbents run campaigns with a deficit any longer, and may run substantial surpluses. ${ }^{2}$

Another advantage which incumbents have is the availability of money at the beginning of the 2-year cycle. With surpluses and early contributions, they can pace themselves better across the campaign and exert an influence on the nature of the opposition which they will eventually face. Until recently, data were not available which would permit analysis of candidates' receipts and expenditures over time. Through automation of their reports, the FEC has begun to make various indexes available which include summary data on candidates' financial activity by report type and time period. ${ }^{3}$ When these data are assembled by quarter across the entire 2-year interelection period, they present a picture of candidate activity which is quite different from what might be expected from the information on total expenditures alone. 
An analysis of such data for the 1978 election cycle shows quite clearly that not only do incumbents spend more money overall than challengers, but they outspend them by substantial amounts early in the campaign. For incumbents, 30 cents of every dollar they eventually spent was allocated before July 1 of the election year, and almost 20 cents was spent before April. In this representative national sample of contested House races, the incumbents spent an average of $\$ 17,170$ in the odd-numbered year, usually long before their challenger was even identified in a midsummer or early fall primary. For their challengers, the average expenditure was less than $\$ 1,000$, equivalent to only about $1 \%$ of their eventual campaign costs. ${ }^{4}$

The sample also contained a limited number of candidates in open races. Their expenditures in the 2 -year period were the highest, almost twice as great on the average as those of incumbents and three times as great as those of the challengers. These expenditures reflect the generally greater levels of competition which are present when no incumbent is seeking reelection. Nevertheless, the off-year expenditures in these open races $(\$ 6,738)$ were less than those of the incumbents and about equal in percentage terms to those of challengers. These data indicate early expenditures by only half (11) of the candidates in open races, presumably because the incumbent did not announce retirement or die until late in the term. Only two of the candidates in open races spent any money at all in the first 6 months of 1977.

The candidate selection process obviously differs for incumbents and the challengers who eventually oppose them. Challengers often face a long road to the nomination which may include competing with other candidates for the right to oppose the incumbent. Because some incumbents are very strong, the opposition party may have to recruit a candidate when none volunteers.

For incumbents, on the other hand, the path to renomination is usually completely within their control. They simply have to decide whether or not to run again. But they may have additional motives which drive their campaign behavior, particularly at the start of the 2-year cycle. They may be insecure in their position and feel the need to start early, with the idea of scaring off a serious challenge or being ready if one emerges. For them, investment may pay off in an easier general election contest. Therefore, some incumbents start spending money long before their actual challenger is ever known.

An incumbent's assessment of electoral risk includes an evaluation of the constituency's partisanship and the candidate's visibility and reputationwhat the incumbent has to start with-and also such qualities of the challengers as their personal characteristics, experience, and financial resources. To capture these various elements in this calculus, the preferred 
TABLE 1. Mean Expenditures over Time for Incumbents and Challengers by Assessments of Their Chances, 1977-1978

\begin{tabular}{lcccc}
\hline & $\begin{array}{c}\text { Total } \\
1977\end{array}$ & $\begin{array}{c}\text { Pre-July } \\
1978\end{array}$ & $\begin{array}{c}\text { After } \\
\text { July 1, 1978 }\end{array}$ & Total $^{\text {s }}$ \\
\hline Incumbents & & & & \\
$\quad \begin{array}{l}\text { Sure Winners } \\
(N=49)\end{array}$ & $\$ 15,285$ & $\$ 12,497$ & $\$ 45,326$ & $\$ 73,108$ \\
Vulnerables & $21 \%$ & 17 & 62 & $100 \%$ \\
$(N=15)$ & $\$ 21,323$ & $\$ 24,400$ & $\$ 122,900$ & $\$ 168,623$ \\
& $13 \%$ & 14 & 73 & $100 \%$ \\
Challengers & & & & \\
Hopefuls & $\$ 1,548$ & $\$ 18,769$ & $\$ 67,049$ & $\$ 87,365$ \\
$(N=43)$ & $2 \%$ & 21 & 77 & $100 \%$ \\
Sure Losers & $\$ 135$ & $\$ 6,009$ & $\$ 20,484$ & $\$ 26,628$ \\
$(N=28)$ & $0.5 \%$ & 23 & 77 & $100 \%$ \\
\hline
\end{tabular}

${ }^{a}$ For the ease of calculating percentages, this total is the sum of the three means.

measure of vulnerability is a survey-based one in which the candidate or a campaign official can provide detailed evaluations of the full range of factors which affect the likelihood of electoral success.

Data are presented in Table 1 which show the relative timing and amounts of expenditures by candidates whose managers varied in their degree of confidence about the chances of winning. The data demonstrate the range of variation in effort and expenditures by candidates of each status. This indicator, measured in September and incorporating information about the campaign's resources as well as those of the challenger, appropriately discriminates levels of spending late in the campaign period. In order to measure the changes in vulnerability which candidates (or their managers) feel, such data should ideally be collected repeatedly across the campaign to reflect changing circumstances. Despite being recorded only at the start of the general election campaign, vulnerability appears to reflect differences in early campaign spending as well, probably because it incorporates characteristics of the district as well as those of the specific opponent. While incumbents on the average clearly outspend their challengers, some types of challengers outspend some types of incumbents.

Incumbents whose managers were confident of victory (Sure Winners) spent less than half as much as those who thought their opponent could make a race of it. Sure winners spent relatively little money early, about $\$ 15,000$ on average in 1977 and another $\$ 12,500$ in the first half of 1978 . The Vulnerables, on the other hand, spent an average of more than $\$ 21,000$ in 1977 , and another $\$ 24,400$ in 1978 before July 1 . The relationship between perceptions of chances and spending by challengers is even 
more dramatic. The very low spenders are candidates who knew they had no chance at all (Sure Losers). But challengers whose managers thought they might beat the incumbent (Hopefuls), even though this almost never happens in practice, spent more than three times as much overall - and more than the Sure Winners. Few of the challengers recorded anything in the way of expenditures in 1977 because they weren't selected yet, but the Hopefuls reported average expenditures of $\$ 18,769$ (related to both the primary and general elections) in the first half of 1978.

An indication of the degree to which preemptive fund-raising and spending may be at work can be found in the relationship between receipts and expenditures over time, particularly in the first 18 months of the campaign period. If candidates only raise and spend what they need at the time, there should be a relatively high and constant correlation between receipts and expenditures over time and across types of candidates. In fact, this turns out not to be the case. While candidates tend to spend most of what they accumulate by the end of the campaign, the relationship is not that strong in the early part of the period.

If "available cash" is defined as the sum of the cash balance from the previous 6-month period plus the receipts during the current one, the correlation between available cash and expenditures is .5 (Pearsonian $r$ ) for incumbents in the last 6 months of 1977 and the first 6 months of 1978; their spending in the early period is only weakly related to available resources. In fact, they are consistently underspending relative to their cash on hand, building larger reserves. But in the last 6 months of the campaign, the correlation rises to .9. Challengers, on the other hand, more consistently spend whatever they collect. In the first half of 1978 , the equivalent correlation between available cash and expenditures for challengers is .7; it is . 9 in the post-July period.

There are many reasons for raising money early in the election cycle. Some incumbents may do it simply to get it over with or because it is easier to make their appeals before potential contributors are solicited by others. While some incumbents may have no intention of publicizing their bankroll in order to discourage strong challengers, others engage in strategic fund raising for preemptive purposes, in order to influence the pool of potential challengers who might oppose them. These motives and behavior require further study. Regardless of their stated intentions, the early money that some incumbents accumulate and advertise probably does act to discourage potential challengers if they know it is there. A definitive demonstration of these effects awaits systematic study of the preprimary period.

In summary, the data available on spending over time suggest that reactive spending captures only part of incumbents' behavior. There are other strategic uses for money beyond beating a general election opponent. 
Money can be raised and spent preemptively to dissuade serious challengers, especially by incumbents who feel vulnerable. Both objective and subjective measures of a candidate's electoral prospects are related to different patterns of resource accumulation and expenditure. Once early campaign expenditures are identified and understood, it is possible to pursue more directly the consequences and significance of reactive spending in the general election period when the incumbents know who their opponents will be.

\section{REACTIVE SPENDING IN THE GENERAL ELECTION CAMPAIGN}

Jacobson (1980a) presented a model of reactive spending by incumbents which suggests they raise and spend money in reaction to how much their challengers spend. As suggested above, incumbents react both to the strength of their challenger and to their perception of their vulnerability in the district. Therefore, two distinct and important conceptual elements should be included in a model of incumbent spending. One deals with characteristics of the district; the other, with the characteristics of the two candidates. It is possible to substitute for Jacobson's 7-variable regression model of incumbent expenditures a 3-variable model which includes measures of both conceptual elements. The three predictors are the following: (1) the challenger's general election expenditures in the post-July 1 period; (2) the assessment that incumbents or their campaign managers make regarding their vulnerability; and (3) a normal vote estimate of the strength of the incumbents' (and challengers') party in the district. ${ }^{5}$

The most significant limitation of Jacobson's original data is the use of 2-year expenditure totals, even though the notion of reactive spending is inappropriate early in the interelection period before the identity of the challenger is known. Treating aggregate expenditures across the entire biennial cycle as a lump sum amount is likely to detract from the explanatory power of any model which applies specifically to the general election campaign. That problem is overcome by including only the post-July 1 expenditures.

The second variable is the incumbents' (or their campaign managers') subjective assessments of the seriousness of their challenges. This variable takes into account the specific facts about the race at hand, such as the previous experience of the challenger and the possible leadership status of the incumbent that Jacobson introduced separately in a series of variables measuring the relative party strength of the two candidates in the district. ${ }^{6}$ The normal vote estimate of the incumbent's party strength is the third variable. It distinguishes between districts which are generally disposed toward the party of the incumbent versus those which are not, largely 
TABLE 2. Determinants of Incumbent Spending in General Election Campaign for a Sample of U.S. House Races, 1978

\begin{tabular}{lcrl}
\hline & $\begin{array}{c}\text { Regression } \\
\text { Coefficient }\end{array}$ & $t$ ratio \\
\hline Constant & 44.10 & & \\
Challenger's Expenditures & .25 & 2.80 & \\
Vulnerability & 41.12 & $3.30 \quad R^{2}=.56$ \\
Normal Vote & -1.77 & $-2.21 \quad(N=63)$ \\
\hline
\end{tabular}

independent of and uncontaminated by recent campaign effects.

Table 2 presents the results of this model which states that:

$$
\mathrm{IE}=f(\mathrm{CE}, \mathrm{VULN}, \mathrm{NV})+e
$$

where IE is the incumbent's post-July 1 general election expenditures, $\mathrm{CE}$ is the challenger's post-July 1 general election expenditures, VULN is the incumbent's subjective assessment of vulnerability, and NV is the normal vote estimate of the strength of the incumbent's party.

This 3-variable model explains substantially more of the variance in incumbents' expenditures than Jacobson's 7-variable model, and it does so with measures which more directly reflect both reaction to challenger behavior and to district characteristics. ${ }^{\top}$ The result predicts a base estimate of about $\$ 44,000$ for incumbent expenditures in the post-July 1 period. Beyond this, incumbents who feel vulnerable are likely to spend an additional $\$ 40,000$. In addition, they are likely to spend $\$ 0.25$ for every dollar spent by their opponent. Finally, incumbents raise and spend almost $\$ 2,000$ additional for every percentage point below 50 that the partisan division in their district falls, and $\$ 2,000$ less for every point above 50 .

Incumbents raise and spend money in reaction to the expenditures of the challenger as well as to their general feelings of vulnerability in this campaign. There is also a long-term component to the model, however, which affects the level of incumbent spending in U.S. House races - the underlying distribution of partisanship in the district as measured through the normal vote. Incumbents representing districts historically sympathetic to their own party spend significantly less money than those from more competitive districts.

It should be emphasized that this now becomes a model of general election campaign expenditures during the post-July 1 period. Incumbents may behave very differently during the first 18 months of their term, as they attempt to dissuade potential challengers from entering the race. Indeed, it can be argued that these early expenditures are extremely im- 
portant in determining incumbency return rates. During the late campaign period, however, the model suggests that their spending behavior can be accounted for by three simple variables: the underlying partisan division in the district, the strength of the challenge, and candidates' own feelings of vulnerability.

\section{DEVIANT CASES: WHAT ELSE AFFECTS HOW MUCH INCUMBENTS SPEND?}

The model presented above accounts for better than one-half of the variance in incumbent spending in the general election period. Although part of the unexplained variation is undoubtedly due to measurement error, examination of deviant cases offers clues about additional factors which may affect how much incumbents spend, clues which provide guidance for future research. ${ }^{8}$

An analysis of the residuals from the regression model showed that 8 incumbents were substantial overspenders, involving amounts $\$ 30,000$ or more above what was anticipated by our model; 3 were substantial underspenders. In addition, 10 incumbents were moderate underspenders, in the range of $\$ 20,000$ to $\$ 30,000$; none were moderate overspenders. A reading of information available in The Almanac of American Politics and other publicly available sources provides further insight into the strategies and motivations of congressional candidates. Two types of situations appear to encourage overspending; two types appear to encourage underspending.

Aspirations for higher party or elective office lead to high levels of expenditures by some incumbents who are electorally safe. They may spend in order to demonstrate their campaign skills or in order to impress colleagues or interest groups with their electoral security. They may try to devastate their current challengers in order to discourage future challenges so that they can be free for a while to concentrate on House business or other concerns outside of their districts. They may also contribute to campaigns run by other candidates in order to establish political debts for future use.

Some candidates overspend for career advancement. Incumbents who are thinking of seeking higher elective or party office may try to demonstrate their money-raising and vote-getting abilities. Some House members have a run for governor or the U.S. Senate in mind, and success at these two fundamental political skills can attract the attention of people back home, especially contributors and campaign organizers. Other members may be interested in advancing along a career path in the House, moving on to positions of greater leadership and responsibility. Raising large amounts of money, and sometimes distributing it to other members of the 
state delegation or fellow committee members, can cement alliances which will come in handy in the future when assignments are being made.

Some incumbents feel especially vulnerable because of unusual personal circumstances associated with their candidacies such as scandal, and there is evidence to suggest that they should be concerned (Peters and Welch, 1980). The dichotomous measure of vulnerability incorporated in the model in Table 2 is inadequate to capture the extra burden of personal scandal which leads some incumbents to outspend their opponents by substantial sums. They view heavy spending as necessary to ensure victory. And even if the outcome is certain, candidates in traditionally safe districts want to return to comfortable margins of victory sufficient to discourage future challenges.

One obvious reason why some incumbents underspend is their inability to raise additional funds. Previous work on campaign finance gives the impression that incumbents have only to ask - that their ability to raise money is virtually unlimited. This impression is misleading when the amounts required are exceptionally large or when the incumbent's fundraising skills are limited. An incumbent from the minor party in a district may have won an upset victory last term when national forces favored his or her party or when the opponent suffered from an unanticipated personal problem. When making their first reelection bids, however, such incumbents may have difficulty raising enough money to secure their seats, especially if the majority party can find a strong opponent to try to recapture the seat.

The more common underspenders are incumbents who feel so safe that they allow their challengers to outspend them. This may come from poor advice from campaign personnel as well as from confidence in the security of the seat. Only frequent and current political intelligence can alert the incumbent to the potential dangers of this strategy and provide a clue as to whether extra fund-raising activity should be undertaken.

\section{CONCLUSIONS}

The role of money in congressional campaigns is neither simple nor direct. Incumbents accumulate money and spend some of it even before their challengers are known. The effects of incumbents' campaign war chests on the strength of their challengers warrants further study. It is plausible to assume that incumbents are concerned about whom their challengers will be and that incumbents act strategically to enhance their security by discouraging serious opposition. Jacobson and Kernell (1982; also Jacobson, 1981) suggested that national economic conditions early in 
the election year affect strategic calculations of potential challengers - that strong challengers choose to run when those economic conditions portend a national shift in their favor and to avoid running when national trends will hurt them. In addition to assessing national forces, these strategically sophisticated challengers also carefully judge the vulnerability of their opponents, including the amount of money available and already in the bank, and the plausibility of someone from their party attracting voter support in the district. Such considerations enter into the challengers' judgment about whether the time is propitious for a successful challenge.

Of course, once the opponent is known, incumbents do react by raising and spending more money in response to well-financed challengers. Reactive spending has been documented in the general election, but it also probably occurs in primary races as well. Moreover, incumbents not only react in terms of total dollars, but also in terms of specific campaign techniques which they choose to employ. In even average television markets, incumbents increase their reliance on television-based appeals in response to television advertising by their opponents (Campbell et al., 1984). They also shift the timing of their appeals in response to their opponents' behavior (Goldenberg and Traugott, 1984).

Although clearly important, the concept of reactive spending alone does not account for all of the systematic variation in how much incumbents spend in their general election campaigns. Some incumbents spend more and others less than anticipated based solely upon the spending of their opponents. Feelings of vulnerability, based upon the underlying level of potential support for the opposition party (measured by the normal vote) or based upon other special circumstances surrounding the race, lead incumbents to spend more. A careful examination of individual cases which are not well explained by the regression model suggests that aspirations for higher elective or party office may also lead incumbents to spend more heavily than anticipated. An inability to raise money or the virtual certainty of winning, regardless of their challengers' expenditures, sometimes produces situations where incumbents spend less than expected. A full model of incumbent expenditures awaits a systematic inquiry designed to test these ideas.

The research reported here has implications for the future study of campaigns as well as for the policy debates over campaign finance. The findings suggest that discussions of alternative systems of public financing of congressional elections should incorporate some consideration of the timing of disbursements by the agency responsible for the funds. Where candidate recruitment is concerned, when money becomes available can make as much difference as how much becomes available. Any procedure 
designed to make the system more equitable by compensating for the advantages of incumbency will need to address the flow of funds to candidates across the full electoral cycle.

Without a required prior demonstration of strength or support in the district, it is hard to imagine how either a central government agency or state and local party organizations could make decisions regarding who is eligible for public money, especially early in the race. Yet, requiring such a demonstration before public funds can be made available would solidify in law another important advantage for incumbents. They would be able to fulfill such requirements long before their challengers.

In addition, ceilings on candidate expenditures may limit the ability of incumbents to maximize their margins. While well-intentioned from the perspective of reducing overall costs and restoring balance to campaigns, undercutting heavy spending may have the unintended consequence of reducing the pool of qualified and experienced candidates for higher elective or political office. Incumbents would be constrained in their ability to demonstrate initiative and competence regarding two of the most important campaign skills - fund-raising and vote getting. Many would undoubtedly turn to other forms of behavior to showcase their interest in advancement.

Finally, if campaigns become federally financed, campaign spending may increase in certain lopsided districts. Whereas some incumbents may not bother to raise and spend much in the face of minimal competition, they may feel compelled to accept federal contributions to their campaigns because their opponents will have more to spend. If heavier expenditures in lopsided districts leads to a better informed citizenry, then federal money would be well spent. However, there are many ways to spend (and waste) money, and merely making more of it available in lopsided races is no guarantee of an improved information environment.

For all of these reasons, it is now evident that more attention needs to be given to the strategic uses of money in the period leading up to the general election campaign. The notion of a campaign should be extended beyond the few months immediately prior to the general election, and the investigation of the strategic uses of money should be expanded beyond consideration of how general election opponents deal with each other.

Acknowledgments. A version of this paper was prepared for the Annual Meeting of the Midwest Political Science Association, Chicago, April 20-23, 1983. Portions of the data collection and analysis presented here were supported by Grant No. SOC 78-18710 from the National Science Foundation. The 1978 CPS American National Election Study data were collected under a grant from the National Science Foundation and supplied by the Inter-university Consortium for Political 
and Social Research. Neither the ICPSR nor NSF bears any responsibility for the analyses presented here. The computing support of the University of Michigan is gratefully acknowledged, as well as the assistance of Kent Cooper at the Federal Election Commission and our colleague John Jackson.

\section{NOTES}

1. Of the 108 districts in the one-in-four sample of the 1978 CPS American National Election Study, 86 had both a Democrat and Republican opposing each other in the race for U.S. House of Representatives. These races form the basis for the analysis presented here, with information obtained from reports of their receipts and expenditures filed with the Federal Election Commission as well as interviews conducted with campaign managers for each candidate before and after the general election, in September-October 1978 and in January-February 1979.

2. Our data show only 4 incumbents with a deficit greater than $\$ 5,000 ; 24$ who essentially broke even relative to their costs (plus or minus $\$ 5,000$ ); 17 who had surpluses between $\$ 5,000$ and $\$ 20,000$; and 23 (one-third of the sample) who had surpluses greater than $\$ 20,000$. For a discussion and examples of large surpluses in the 1982 elections, see Kenneth Noble's article in The New York Times, "Some in House Using Excess Cash For Expensive Living" (April 5, 1983). For 1984, George Lardner Jr's article in The Washington Post National Weekly Edition, "How Much for a House Seat?" (April 29, 1985), describes how costs declined in 1984 but surpluses reached a record level.

3. The data on receipts and expenditures over time were assembled from the series entitled "Candidate Index of Supporting Documents-(E)." This is a summary of each candidate's dollar totals of receipts and expenditures with an indication of the election type, general or primary, as recorded by the candidate.

4. As Jacobson (1981) pointed out, the 1978 sample includes too few strong challengers to be representative of all House elections that year. If anything, that direction of bias in the sample probably leads to an underestimate of the amount of preemptive spending by incumbents.

5. Estimating the normal vote with reliability for a large number of congressional districts is relatively difficult, but a reasonable estimate has been derived (Goldenberg and Traugott, 1984 ) and is used in this analysis.

6. Most researchers will not have survey-based measures of vulnerability available to them. In order to assess the relationship between the dichotomous variable used here and other more easily accessible data, a logit regression was run to predict incumbents' perceived vulnerability (distinguishing Sure Winners from Vulnerables) as a function of number of terms served, the difference between the 1976 vote margin and the district's normal vote, and the occurrence of a scandal during the last term. These measures were obtained from the Almanac of American Politics. Together, these three variables explain $63 \%$ of the variance in the indicator of vulnerability, which is significant at the .02 level. The coefficients in the resulting equation, and their standard errors, are:

Constant

Number of terms

1976 deviation from normal vote

Presence of scandal

$\begin{array}{rr}-.0426 & .552 \\ .2502 & .174 \\ .0670 & .043 \\ .0335 & .029\end{array}$

7. Jacobson presented a regression equation as an estimation of his model for House races in 1978, based upon all 305 incumbents who faced opposition, which accounts for $35 \%$ of the variance in incumbent spending. This equation was replicated as precisely as possible in 
our sample of 71 incumbents who faced opposition, although some slight differences in certain independent variables probably remain. These differences may result from sampling errors, from slight differences in measurement, or from a bias in the sample of districts as Jacobson has suggested (1981). In our replication of Jacobson's model, the equation explains $44 \%$ of the variance in incumbent spending and serves as the appropriate baseline for comparison with alternative specifications of the model.

There are two important ways in which the measures of reactive spending used by Jacobson can be improved in order to enhance the model's predictive power. The first involves using only general election expenditures by incumbents and their challengers rather than the 2-year totals. The second is to use an alternative measure of the strength of the challenger's party (CPS). Jacobson used the two-party vote share received by the opponent's party in the previous election as a measure of the relative strength of the two parties in the district. Yet, the concept calls for a baseline measure of partisan support against which the campaign effects of spending can be evaluated; Jacobson's measure is contaminated by campaign effects in the previous contest. A more appropriate measure of underlying partisan strength in the constituency is an estimate of the normal vote in the congressional district (Converse, 1966; Goldenberg and Traugott, 1981). With these improvements, the predictive power of Jacobson's model of reactive spending is increased by one-third, from $44 \%$ to $58 \%$. The estimate moves from 27 cents per challenger dollar to almost 40 cents. There are certain other differences in the regression coefficients for some of the variables in the sample of races. In particular, the party variable drops to insignificance in the revised version. This may be due to the exclusion of money allocated to primaries in the measures of challengers' and incumbents' expenditures.

8. There are several sources of error in variability. One is the variable used to capture general election expenditures. Although many primaries are over before July and some pre-July expenditures are appropriately considered general election spending, the choice of July 1 as the beginning date for general election expenditures does not appear to cause any methodological difficulty. Alternative equations were run predicting 1978 general election expenditures where the measure captured all such expenditures after January 1, 1978, and the results were virtually identical to those reported in Table 2. However, all FEC documents rely upon the campaign's designation of expenditures as "primary," "general," or "other," and the meaning of these designations is not always clear. Just before the primary, spending is attributed to the primary. But what is spent long before the primary might be labeled either "primary" or "general" election expenditures. The significance of the post-July figures is that they provide a standard for aggregating expenditures for a period which corresponds to the usual conception of the general election campaign and during which both opponents have already been selected. By including in the regression models only those general election expenditures made post-july, an incumbent's or a challenger's expenditures are sometimes underestimated. On the other hand, there is reasonable certainty that by July 1 the challenger is known and reactive spending is possible. The larger lesson here is that campaigns do not always distinguish between primary and general election spending, and perhaps it is necessary to broaden our view even further to look at the flow of money throughout the entire campaign. To do so requires detailed data on the amounts and purposes of expenditures over time, and that demands significant data collection and coding resources.

A second source of measurement error is the estimate of the district's normal vote. Because adequate survey results were not available from each of the districts of interest, the normal vote had to be estimated through regression techniques referenced in note 5 . Overall, this estimate has proved to be quite successful for systematic analysis, but errors in a specific estimate could contribute to a few large residuals. 
Finally, the measure of uncertainty employed in Table 2 is dichotomous, although candidates obviously vary in terms of how uncertain they feel, and any one candidates level of uncertainty may vary across the course of the campaign.

\section{REFERENCES}

Barone, Michael, Ujifusa, Grant, and Matthew, Douglas (1979). The Almanac of American Politics 1980. New York: E. P. Dutton.

Campbell, James E., Alford, John R., and Henry, Keith (1984). Television markets and congressional elections. Legislative Studies Quarterly 9:665-678.

Converse, Philip E. (1966). The concept of a normal vote. In Angus Campbell, Philip E. Converse, Warren Miller, and Donald E. Stokes (eds.), Elections and the Political Order, pp. 9-39. New York: Wiley.

Cover, Albert D. (1977). One good term deserves another: The advantage of incumbency in congressional elections. American Journal of Political Science 21: 523-542.

Cover, Albert D., and Brumberg, Bruce S. (1982). Baby books and ballots: The impact of congressional mail on constituent opinions. American Political Science Review 76:347-359.

Fenno, Richard F. Jr. (1978). Home Style; House Members in their Districts. Boston: Little, Brown.

Fiorina, Morris P. (1974). Representatives, Roll Calls and Constituencies. Lexington, Mass.: D. C. Heath.

Fiorina, Morris P. (1977). The case of the vanishing marginals: The bureaucracy did it. American Political Science Review 71:177-181.

Goldenberg, Edie N., and Traugott, Michael W. (1984). Campaigning for Congress. Washington: Congressional Quarterly Press.

Hinckley, Barbara (1980). House reelections and Senate defeats: The role of the challenger. British Journal of Political Science 10:441-460.

Jacobson, Gary C. (1978). The effects of campaign spending in congressional elections. American Political Science Review 72:469-491.

Jacobson, Gary C. (1980a). Money in Congressional Elections. New Haven: Yale University Press.

Jacobson, Gary C. (1980b). Congressional elections, 1978: The case of the vanishing challengers. Paper presented at the Conference on Congressional Elections, Rice University and the University of Houston, Houston, Texas, Jan. 10-12.

Jacobson, Gary C. (1981). Strategic politicians and congressional elections, 1946-1980. Paper presented at the Annual Meeting of the American Political Science Association, New York, Sept. 3-6.

Jacobson, Gary C. and Kernell, Samuel E. (1982). Strategy and Choice in Congressional Elections. New Haven: Yale University Press.

Lardner, George Jr. (1985, April 29). How much for a House seat? The Washington Post National Weekly Edition.

Mayhew, David R. (1974a). Congress: The Electoral Connection. New Haven; Yale University Press. 
Mayhew, David R. (1974b). Congressional elections: The case of the vanishing marginals. Polity 6:295-317.

Noble, Kenneth B. (1983, April 5). Some in House using excess election cash for expensive living. New York Times.

Peters, J. G., and Welch, S. (1980). The effects of charges of corruption on voting behavior in congressional elections. American Political Science Review 74:697-708.

Ragsdale, Lyn (1981). Incumbent popularity, challenger invisibility, and congressional voters. Legislative Studies Quarterly 6:201-218.

Traugott, Michael W, and Goldenberg, Edie N. (1981). Normal vote analysis of U.S. congressional elections. Legislative Studies Quarterly 6:247-257.

Welch, William P. (1980). The allocation of political monies: economic interest groups. Public Choice 35:97-120. 